offers synthetic chemists the ability to accomplish challenging chemical transformations without the need for expensive, toxic or environmentally sensitive metal-based catalysts. Despite several advantages, the adoption of organocatalytic reactions in large-scale synthesis is hindered by the relatively poor turnover efficiency of many catalysts, which necessitates high loading and recycling them through expensive re-isolation techniques. Heterogeneous catalysis offers a possible solution to this problem; removal of a solid-supported catalyst from a reaction solution requires no techniques more complex than filtration.

Now, a team of researchers from Germany and Korea led by Klaus Opwis and Benjamin List have developed a simple and general approach to immobilizing organocatalysts on a nylon textile. When nylon is irradiated with UV light in the presence of an alkenebearing organocatalyst, radicals generated at the surface of the fibres react with the catalyst in solution. The result is the permanent functionalization of the fabric surface with the active catalyst and Opwis, List and colleagues prepared three 'organotextile' catalysts in this way. A Lewis-basic dimethylaminopyridinederived catalyst and a highly Brønsted-acidic sulfonic acid catalyst were shown to carry out acylation and hydroetherification reactions, respectively. Crucially, after removal from the reaction solution and rinsing, the organotextiles could be reused several times without loss in activity. Finally, a cinchona alkaloid-based organotextile catalyst carried out desymmetrizing methanolysis of mesoanydrides with comparable enantioselectivity to the homogeneous form of the same reaction. In this process, a single organotextile was recycled over 200 times without a drop in reaction stereoselectivity.

Easy extraction is not the only advantage heterogeneous catalysts offer, their use in continuous-flow reactors for large-scale syntheses is far more convenient and efficient than batch techniques. Opwis and List also prepared one gram of a useful enantiopure product - in quantitative yield - using an iterative continuous-flow reaction with a reaction column loaded with the cinchonaalkaloid-functionalized organotextile.

\section{PIGMENT DEGRADATION}

\section{Chrome yellow's darker side}

Angew. Chem. Int. Ed. http://doi.org/ł2dzcp (2013)

'Chrome yellow' paint pigments - lead chromate species that sometimes contain sulfate - are often found in late-nineteenthcentury artwork, for example Van Gogh's Falling Autumn Leaves (Les Alyscamps; pictured). They are known to gradually

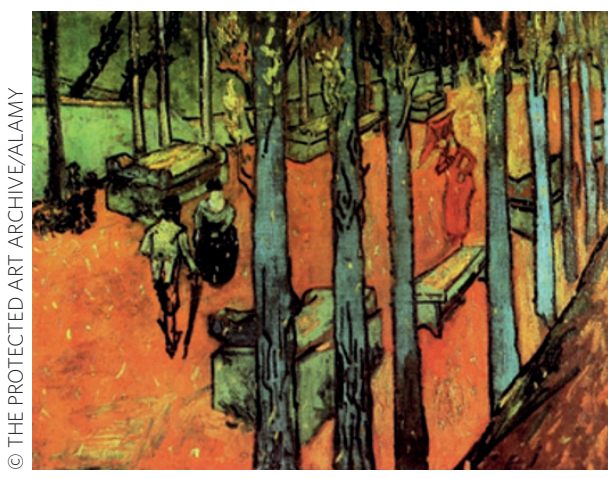

\section{blog $_{\text {roll }}$ 空}

\section{Exposing fraud}

Should bloggers highlight questionable research articles, and if so, how?

Paul Bracher, who blogs at ChemBark, was the first to write about the now infamous "just make up an elemental analysis"

darken on exposure to sunlight, and understanding the degradation process is important to the storage and restoration of these paintings. Recent studies have shown that the degradation rate depends on the pigment's crystalline structure and also its sulfate concentration - sulfur-rich, orthorhombic species darken more rapidly.

Using scanning transmission electron microscopy and electron energy-loss spectroscopy with high spatial and energy resolution, He Tian from the University of Antwerp, Belgium, and co-workers have now studied the degradation of a centuryold bright-yellow oil-paint sample at the nanoscale. The sample was characterized before and after an artificial ageing treatment - a 40-day UVA-visible light irradiation that converts it from bright yellow to deep brown. They observed that the original and aged samples comprised four types of particle, with a size distribution ranging from 20 to $300 \mathrm{~nm}$, some of which had core-shell morphologies. The particles consist of phases of $\mathrm{PbCrO}_{4}, \mathrm{PbSO}_{4}$ (often observed together, suggesting a solid solution $\mathrm{PbCr}_{1-x} \mathrm{~S}_{x} \mathrm{O}_{4}$ ) and $\mathrm{Cr}_{2} \mathrm{O}_{3}$ (either as small particles or forming the shell of larger particles). Electron energy-loss near-edge structure spectra showed that the $\mathrm{PbSO}_{4}$ phases remained unchanged on degradation, whereas a significant amount of $\mathrm{PbCrO}_{4}$ was converted into $\mathrm{Cr}_{2} \mathrm{O}_{3}$ - and this process was faster for sulfur-rich phases.

Combining these findings with previous observations on this material, Tian and colleagues propose a model for the ageing process in which $\mathrm{PbCrO}_{4}$ converts into $\mathrm{Cr}_{2} \mathrm{O}_{3}$ through the dissolution of chromate ions. These ions undergo a reduction reaction at the interface between the paint and surrounding microdroplets of aqueous solution, and precipitate as $\mathrm{Cr}_{2} \mathrm{O}_{3}$ at the surface of all of the particles. This model agrees well with the ageing process observed for all four types of particle.

Written by Enda Bergin, Paul MacLellan, Leonie Mueck and Anne Pichon paper in Organometallics (http://go.nature. com/4Uh53Z) and he more recently raised questions about some peculiar NMR spectra in Organic Letters (http://go.nature.com/ xlxm8N). Similarly, Mitch André Garcia of Chemistry Blog brought attention to some questionable TEM images in Nano Letters (http://go.nature.com/5gXvDm).

Some have asked whether blogs are an appropriate venue for exposing dubious work. Even Garcia has criticized Bracher for "[losing] sight of the line between witch hunting and the proper responsibilities of the online chemical community" (http:// go.nature.com/YzPPOv). In defence, Bracher points out that by raising concerns about other scientists' work publicly, he puts his own reputation and credibility on the line (http://go.nature.com/guiP2X).

Derek Lowe, at In The Pipeline, reflects on who should look for and expose faked papers (http://go.nature.com/XThEWE). Lowe believes that making a public spectacle out of fabricated work acts a deterrent, but he doesn't intend to turn his blog into the chemical literature police. Instead, he prefers that those most harmed by a suspicious paper challenge it themselves. In a subsequent post (http://go.nature. $\mathrm{com} / 28 z u Z P$ ) commenters debate what action is appropriate for unreproducible papers - suggestions included publishing a rebuttal and simply "turn off your web browser and get back to work".

Finally, on a less serious note, John Spevacek at It's a Rheo Thing considers what he would do to win a competition held in Paris at a screening of the lg Nobel awards show (http://go.nature.com/VK5r8Y). It's a competitive take on the pitch drop experiment, in which one must prepare the slowest flowing mixture possible out of kitchen ingredients, but with a catch — it has to drop before the end of the show.

Written by Tom Phillips, who blogs at http://blog.tomwphillips.co.uk 